\title{
Reflexões acerca do reconhecimento visual do Clube Caixeiral de Rio Grande, RS
}

Reflections on the visual recognition of the Clube Caixeiral de Rio Grande, RS

Reflexiones sobre el reconocimiento visual del Clube Caixeiral de Rio Grande, RS

Gianne Zanella Atallah

João Fernando Igansi Nunes

\section{Resumo}

$\mathrm{O}$ artigo pretende estabelecer uma relação entre o presente e o presente tendo como objeto o Clube Caixeiral de Rio Grande, RS, a partir do reconhecimento visual no contexto em que está inserido, e compreender como isso influiu em frequentadores que por ali passaram. Essa análise pretende demonstrar o quanto os sentidos da memória podem exercer uma situação favorável diante das fontes, sejam elas materiais (suportes) ou imateriais (lembranças), a partir de pontos de referência estabelecidos pela memória dos locais.

Palavras-chave: Clube Caixeiral. Memória dos locais. Rio Grande.
Compreender um objeto de estudo a partir de sua contextualização transitória - o que observamos, mas não reconhecemos desafia uma discussão sobre o valor memorial de uma materialidade ainda existente e sobre seu papel no tempo presente, tendo como enfrentamento a relação que estabeleceu com o passado, a partir do reconhecimento visual que acontece da observação do cotidiano e do registro desse espaço em imagens.

\footnotetext{
Doutora em Memória Social e Patrimônio Cultural pela Universidade Federal de Pelotas (2018). Professora de História da rede municipal de Rio Grande. E-mail: gizaatallah@gmail.com

** Doutor em Comunicação e Semiótica pela PUC/SP. Professor adjunto do Centro de Artes da Universidade Federal de Pelotas. E-mail: fernandoigansi@ gmail.com
}

Recebido em 02.08.2018 - Aprovado em 14.09.2018 http://dx.doi.org/10.5335/hdtv.19n.1.9053 


\section{A significação simbólica}

“A paixão do passado [...] deveria suscitar mais o interesse do que inquietudes" (2009, p. 15), assim nos diz Tornatore. Essas inquietudes em sua máxima nos fizeram refletir sobre nossa relação com o passado, um passado presente que nos é estrangeiro. Identificamos, percebemos sua presença, mas ele é dotado de incógnitas diante das memórias social e histórica, mesmo que ambas contestem entre si esse passado.

Assim, o passado que nos inquieta é o do próprio Clube Caixeiral de Rio Grande, RS (CCRG/RS) - enquanto espaço físico (práticas) e moral (costumes) -, pois em nosso entendimento os locais suscitam a memória do reconhecimento sobre o corpus que habita neles. Esse corpus é a própria memória do lugar; nessa perspectiva, Assmann nos apresenta a "memória dos locais":

[...] a expressão é sugestiva porque aponta para a possibilidade de que os locais possam tornar-se sujeitos, portadores da recordação e possivelmente dotados de uma memória que ultrapassa amplamente a memória dos seres humanos. A força sugestiva dessa opacidade é um bom ponto de partida para investigar a seguir o que a "memória dos locais" guarda em si (2011, p. 317).

A trajetória caixeiral na cidade de Rio Grande é anterior à fundação do clube em 1895, que, com toda a persistência dos membros, se instaurou em 1912 com a inauguração da sede social no endereço atual. Essa ocasião foi registrada como um momento que ressignificaria o novo lugar; e o prórpio registro, com crianças à frente do prédio, enaltece isso. Filhos de sócios, com uma vestimenta adequada ao momento, asseguram o valor de uma nova trajetória, a entidade enquanto seus aspectos político e social (Figura 1). A sede mantém uma resistência contra a perda, o "luto" propriamente dito (Figura 2). $\mathrm{O}$ passado procura o seu reconhecimento não como "lugar" de acontecimentos de uma associação classista recreativa, mas como o valor da luta pelo reconhecimento trabalhista e pela evolução comercial do lugar de origem, junto com outras atividades comerciais, industriais, que alavancaram o poder econômico da cidade de Rio Grande, RS (Figura 3).

Figura 1 - Prédio do CCRG inaugurado em 03 de maio de 1912

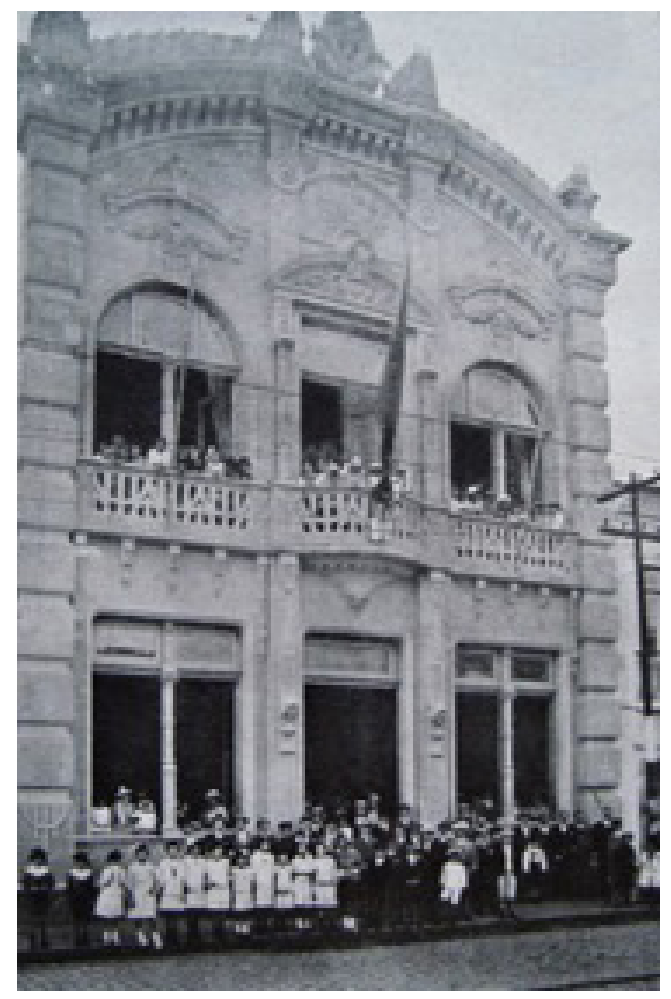

Fonte: acervo do jornal Correio do Povo (05 mar. 2012). Fotógrafo não identificado. 
Figura 2 - Prédio do CCRG atualmente

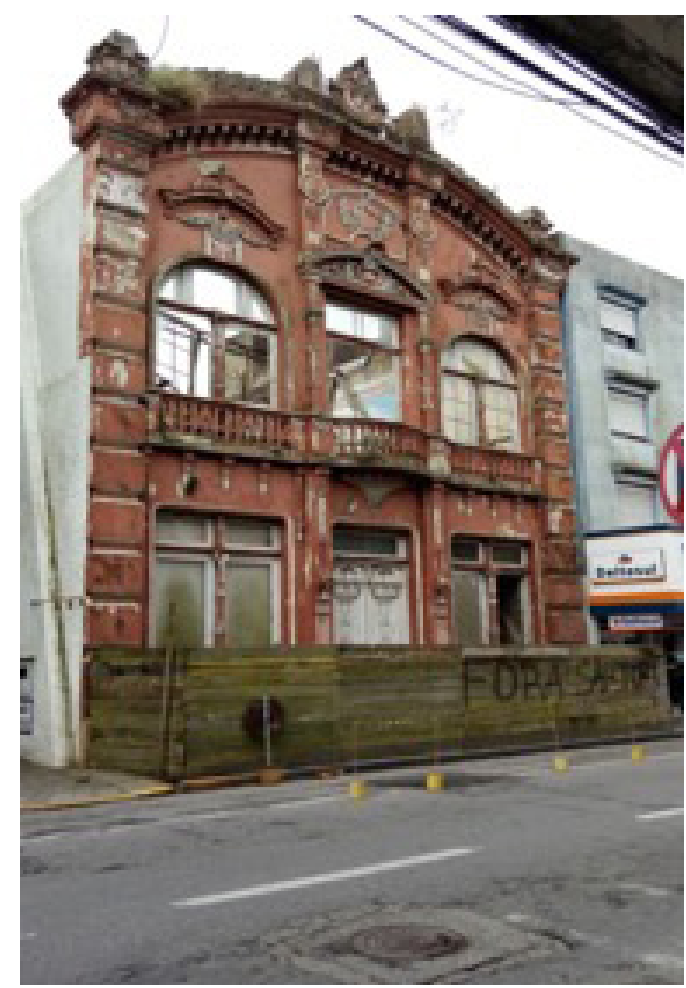

Fonte: acervo pessoal de Gianne Zanella Atallah (27 out. 2016).

Observar as imagens (Figuras 1 e 2) leva-nos a tentar compreender qual o diálogo que ambas mantiveram com a sociedade, e concluímos que o diálogo já era o mesmo num espaço temporal diferenciado. Em 1980, o local já suscitava suas memórias, apegava-se a um tempo vivido, entendendo-se como o próprio sujeito do seu presente, mas esse presente tornou-se passado. Novamente essa tentativa de diálogo se repete, ou seja, a sociedade não consegue ouvir o seu objeto, o CCRG/RS não consegue dialogar diante da herança do passado e não se reconhece como sujeito de si mesmo.
O edifício descrito no Decreto $n^{\circ} 15.205$ (PREFEITURA DE RIO GRANDE, 2018), de 24 de janeiro de 2018, caracteriza-se por ter sido construído

[...] em estilo eclético, com vertente Art-Noveau, cujos detalhes dos elementos arquitetônicos e artísticos fazem referência à sociedade e aos setores econômicos pujantes que o erigiam, apresentando no ápice da sua platibanda, um medalhão com a cabeça de Mercúrio com capacete alado, sobreposta a uma roda dentada, símbolos do comércio e da indústria (PREFEITURA DE RIO GRANDE, 2018).

Esse estilo inseria-se em um conjunto de construções que acompanhavam os mesmos pressupostos, e, apesar do curto período de construção, a categoria, com muitos sacrifícios, empenhou-se em angariar fundos para tal propósito.

Figura 3 - Detalhes da fachada principal do CCRG

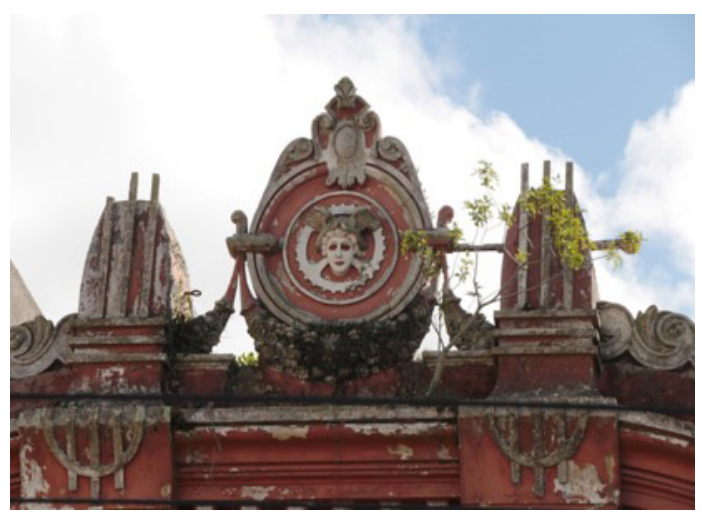

Fonte: acervo pessoal de Gianne Zanella Atallah e fotografia de Aldivo Branco Mendes (set. 2017). 
Figura 4 - Detalhes da fachada principal do CCRG

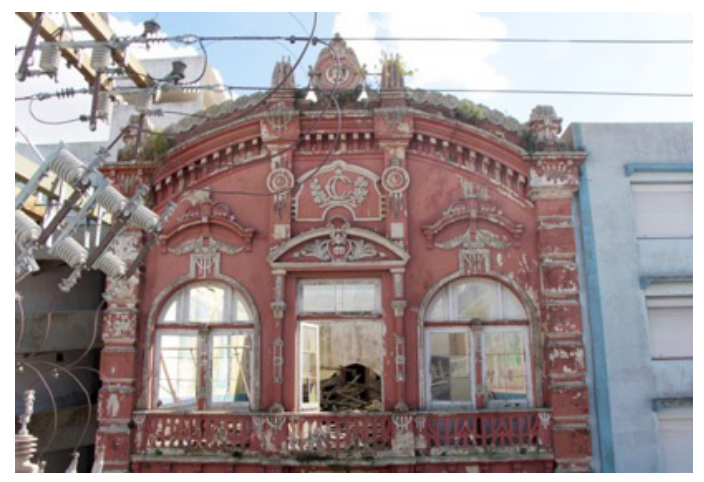

Fonte: acervo pessoal de Gianne Zanella Atallah e fotografia de Aldivo Branco Mendes (set. 2017).

De acordo com a Ata do Clube $n^{\circ} 290$, de 05 de maio de 1910:

[...] houve uma discussão sobre o estilo da construção do prédio, que deveria ser um edifício assobradado ou sobrado (construção com dois pavimentos). Foi estudada uma planta provisória traçada a lápis apresentada pelo Sr. Albino Vaz Dias, que previa a entrada principal no centro do edifício, ficando à sua direita e à sua esquerda uma casa de porta e janela que poderiam ser alugadas durante o tempo em que o Club não necessitasse delas para si mesmo. ${ }^{1}$

No dia 22 de fevereiro de 1911, de acordo com a Ata $n^{\circ} 36 \mathrm{~A}^{2}$ uma assembleia foi convocada para tratar da construção da sede do clube. Foram analisadas as propostas dos senhores João Baptista Feijó, Mathias da Silva Oliveira e Eduardo Tavares Esgueira, e foi escolhida a de Esgueira, que aceitou construir o prédio pelo valor de sessenta e dois contos de réis. O clube, em acordo com o senhor Eduardo Tavares Esgueira, realizou um empréstimo não superior a cinquenta contos de réis, dando como garantia a hi- poteca do prédio a construir, assim como o terreno.

Em 03 de maio de 1911, de acordo com a Ata $n^{\circ} 37 \mathrm{~A},{ }^{3}$ foi lançada a pedra fundamental do clube. No dia 14 de julho de 1912, de acordo com a Ata $n^{\circ} 42 \mathrm{~A},{ }^{4}$ foi realizada, no Salão Nobre da Intendência Municipal de Rio Grande, uma sessão solene para abertura da Exposição Municipal promovida pelo CCRG/RS, com patrocínio da Intendência Municipal e comemorativa à inauguração do palacete social do CCRG/RS, na Rua Marechal Floriano, nos $n^{\text {os }} 168$ e 172, estando várias autoridades civis e militares presentes, o corpo consular, representantes da imprensa e de diversas associações, a diretoria do clube, os membros do conselho deliberativo e diversos associados. Ressaltamos que, no período de 1895 a 1912, o CCRG/RS teve outros endereços que se situavam próximos ao endereço citado.

A aquisição do bem imóvel era uma situação já observada em clubes caixeirais de outras localidades do estado do Rio Grande do Sul. Possuir uma construção imponente, em conformidade com o corpus que a habitava, construída segundo o estilo da época e do seu entorno (Figuras 5, 6, 7 e 8) localizada em uma das ruas centrais da cidade, significava tanto a luta por direitos, como por status social:

[...] buscavam preferencialmente se instalar no centro da cidade, afinal o lócus privilegiado da política [...] havia a preferência por determinado logradouro da região central [...] o endereço da sede fazia parte da representação pública da associação (BATALHA, 2009, p. 260-261). 
A representação pública era uma forma de se mostrar diante de outras instituições, como estabelecimentos comerciais, clubes com origens diversas; era a forma de um poder que emanava de desejos, mas que confirmava a influência diante dos outros.

Figura 5 - Rua Marechal Floriano esquina com rua Duque de Caxias, em frente à praça Telles, atualmente praça Xavier Ferreira, 1900

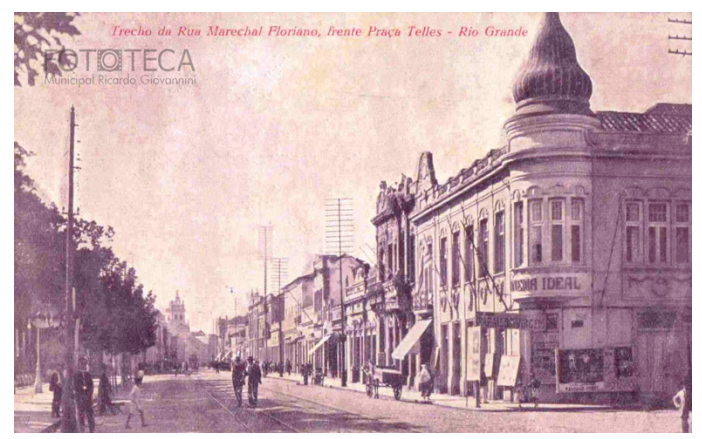

Fonte: acervo da Fototeca Municipal Ricardo Giovannini.

Figura 6 - Praça Telles, atual praça Xavier Ferreira

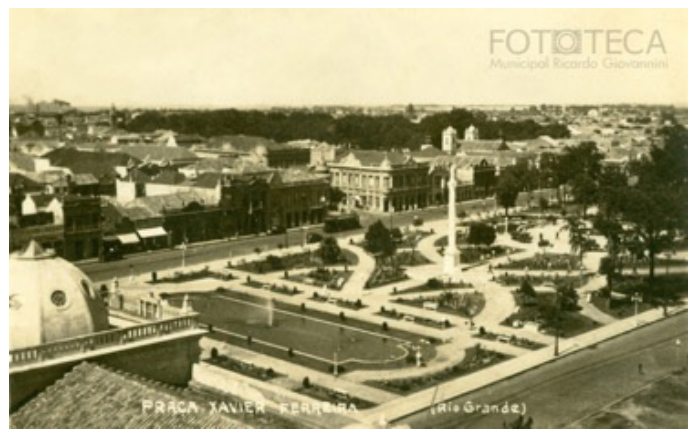

Fonte: acervo da Fototeca Municipal Ricardo Giovannini.

No entorno (Figuras 5, 6, 7 e 8) onde estava situado o CCRG/RS, concentrava-se uma variedade comercial e de entretenimento, inclusive clubes como a Associação dos Empregados do Comércio (primeiramente onde atualmente se encontra a loja América; depois com sede própria, na atual Galeria São Pedro, entre as ruas Duque de Caxias e General Neto), que vem há cerca de dois anos, aproximadamente, encerrando suas atividades e vendendo a sede social. Outro clube era o Grêmio Lusitano (na Rua Duque de Caxias), situado primeiramente no andar superior da edificação onde atualmente funciona a loja Gaston (anteriormente Café Dalila) e posteriormente no prédio em frente, onde atualmente funciona o Banco Santander (calçadão, na Rua General Bacelar). O Clube do Comércio, situado na Rua Osório, é ladeado pelos prédios do mercado municipal e da alfândega. E o Clube Carnavalesco Saca-Rolhas, na Rua Marechal Floriano, foi formado por portuários. Esses clubes mantiveram outros endereços antes da sede oficial, mas registramos que sempre na região central.

\section{Figura 7 - Mercado municipal}

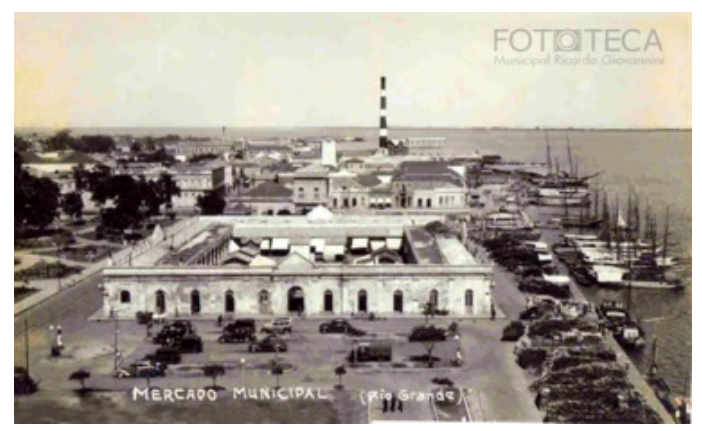

Fonte: acervo da Fototeca Municipal Ricardo Giovannini.

Figura 8 - Trecho da rua Marechal Floriano onde se localiza a alfândega

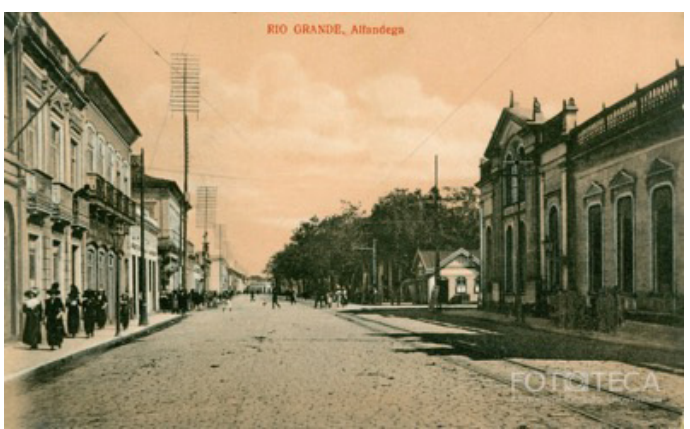

Fonte: acervo da Fototeca Municipal Ricardo Giovannini. 
Possuir uma sede era uma forma de, segundo Batalha, revisitar ideais antigos e, ao mesmo tempo, consolidar a tradição.

Para muitas sociedades, o ápice do pretígio era serem proprietários de sua sede, possuírem um endereço permanente. Essa era a forma de demonstrar solidez e uma tradição consolidada - a tal ponto que esse objetivo não raro constava dos estatutos associativos como algo que as sociedades deveriam alcançar (2009, p. 262).

A tradição de possuir o prédio e mantê-lo no tempo presente reforça a forma como lidamos com a tradição inventada, uma ritualização da instituição como forma de força e vitalidade aos ideais do grupo. Segundo Eric Hobsbawn e Terence Ranger (1997), desde a Revolução Industrial, as tradições classificam-se em três categorias superpostas: a) aquelas que estabelecem ou simbolizam a coesão social ou as condições de admissão de um grupo ou de comunidades reais de artificiais; b) aquelas que estabelecem ou legitimam instituições, status ou relações de autoridade; e c) aquelas cujo propósito principal é a socialização, a inculcação de ideias, sistemas de valores e padrões de comportamento (HOBSBAWN; RANGER, 1997, p. 17). As três categorias citadas por Hobsbawn e Ranger (1997) são reconhecidas no clube enquanto objeto de personificação que está além do espaço físico simplesmente.

Essa tradição é uma construção do meio e do grupo que a produziu e deverá ser simultaneamente passada para um tempo futuro, pois, mesmo que de maneira informal, ela dá sustentação à memória coletiva.

Podemos analisar esse aspecto na descrição do espaço-clube internamente feita por alguns entrevistados no tempo presente, a partir de suas memórias em temporalidades e convivências diferentes sobre o clube.
Segundo o senhor Regys,

Depois de um tempo com aquele problema estrutural que o Caixeiral teve, essas boates foram transferidas do salão principal e foi feita então no andar térreo. Então, se a gente for pensar na planta do caixeiral, quando tu entra ali, a entrada principal, no corredor à esquerda, tem, ou tinha, um acesso, tinha uma secretaria ali também, parte da secretaria. E, lá no fundo, tinha um salão também, um salão com bar, ali também, por um bom tempo, foram feitas as boates do caixeiral. Evidentemente, que as melhores foram as de cima, um ambiente maior, enfim. Emocionalmente falando, as boates de cima tinham maior impacto. Nesse lugar lá de baixo, também, além das boates, e a gente se reunia em outros dias da semana para jogar sinuca, pingue-pongue. Também se reunia ali a gurizada, para fazer esse tipo de entretimento. ${ }^{5}$

O problema estrutural a que o senhor Regys se refere ocoria principalmente em bailes de carnaval: quando os foliões dançavam aceleradamente, o prédio tremia, balançava o andar superior. Além disso, por manutenção, o prédio esteve com atividades suspensas algumas vezes durante a sua trajetória.

Ele ainda ressalta:

teve também um período que os bailes de carnaval do Caixeiral não foram feitos aqui na Marechal Floriano, pela questão da estrutura que estava em risco. Então eles foram feitos onde era localizada a discoteca ou boate Arco Íris, quando foi na Tiradentes, acho que hoje é o Autopeças Garcia ou um depósito deles [...]. Talvez tenha sido na década de $80 . .81,82,83$, não saberia te dizer. ${ }^{6}$ 
A memória se delineia pelos sentidos do corpo humano: visão, tato, olfato, paladar e audição de cada indivíduo. Acerca do objeto em questão, pela memória social, pelo afeto e por seu oposto, o desafeto, reconhecemos essa memória por um dos cinco sentidos. O senhor Regys, ao falar da boate e dos jogos, evidencia que sua memória com relação ao espaço do clube é auditiva, pois remete a sinais musicais, à emoção de estar ali, e os afetos que estabelece são a partir da musicalidade dos objetos.

Já no relato de dona Zoraia sobre o espaço do clube, percebemos que as suas memórias são feitas de uma trajetória visual:

O prédio embaixo, dos dois lados, era a secretaria, eu me lembro que a gente tinha acesso direto ao salão pelas escadas, a parte de uma toda era o salão, as portas se abriam, era o lugar que tinha ventilação. As portas de vidro, as paredes eram todas com aquelas escariolas, todas eram pintadas, lindíssimas! No fundo, à direita, saindo do salão, ficava a copa, tinha um balcão grande de madeira, era uma copa bem grande. $E$ acho que na continuação era $o$ banheiro masculino e, do lado esquerdo, para o fundo, quando saía do salão, era o banheiro feminino, que até pouco tempo, quando a escola de tai chi [chuan] usou, o banheiro se mantinha. A gente usava 0 banheiro antigo, tinha azulejos antigos, tinha uma pia, pelo menos, bem antiga, um espelho, aqueles espelhos muito antigos. ${ }^{7}$

A visita memorial que dona Zoraia se permite fazer, entrando nos espaços internos do clube, demonstra uma memória tátil e visual; ela toca o passado com os olhos, ela permite a sua memória, a lembrança dos ele- mentos que constituem o objeto em si. Dona Zoraia nos permite ver um passado vivenciado por ela:

Quando eu fiquei sabendo que tinha bah, eu queria fazer tai chi [chuan] não sei o quê... -, me disseram no Caixeiral... "Como assim no Caixeiral?!" Realmente, tu resgata, tu volta, tu revive, e tu entra lá dentro, - vamos dizer que tu fecha os olhos - tu enxerga as pessoas. Parece que tu volta, entra naquele clima, naquela coisa de realmente de reviver uma parte, e é retomar, reviver uma coisa lá de adolescente, que tipo nunca imaginei de um dia voltar a entrar no Caixeiral. Realmente eu nunca imaginei poder entrar, porque era uma coisa fechada, não funcionava mais nada, e, de repente, a escola estava dentro. E eu gostei muito, eu gostava muito de ficar ali. Até continuei na escola depois, um bom tempo, mas foi muito doloroso sair dali. Que tu via, no momento que a gente estava saindo, abandonando o prédio, não ia ser resgatado nada. Que se ficou o tempo que se pôde. ${ }^{8}$

O detalhe de cada elemento é o apoio de sustentação de uma lembrança que revela uma saudade vivida. Segundo dona Ydna,

No caixeiral era assim, entrava e no lado esquerdo tinha um corredor bem largo, se ia e desemboca lá no fundo... era a copa, o restaurante. Se tu subisse a escada, dobravas à direita, e entrava no salão. Eu vou te mostrar aqui ó [mostra fotos]. Isso aqui é uma foto de família, quando mamãe casou em 32 [...] eram umas cortinas de veludo, ao fundo era azul marinho e depois aqui era meio dourado [Figura 9]. Ai, que bom! Aqui, me lembrei! A mamãe bordava à máquina, e todo $\mathrm{o}$ ano que ela fez, 
eu não sei quantas dezenas de cadeiras bordadas com o emblema do caixeiral [...] e esta foto que eu encontrei aqui é o outro lado do salão, a gente aqui tinha um corrimão, então ali ó era a parte de trás dos andares de cima. E sabe onde é que ficavam a orquestra, os conjuntos? No mezanino aqui em cima, em cima da escada. Então, ali ficavam os músicos. ${ }^{9}$

Figura 9 - Bodas de pérola de Mário Corrêa Alvaro (presidente do clube) e Leonor Alvaro, pais de dona Ydna, em 27 de fevereiro de 1952, no Clube Caixeiral de Rio Grande

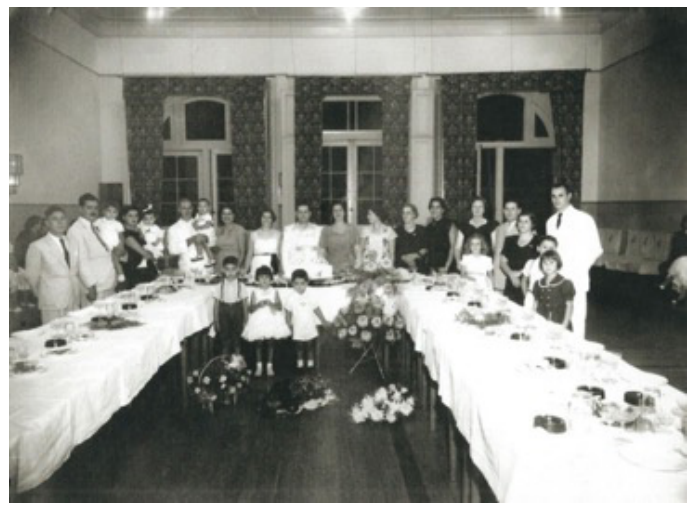

Fonte: acervo pessoal de dona Ydna Alvaro Martinez.

Dona Ydna vivenciou o clube a partir de sua família, e sua memória reúne, pelo menos, quatro importantes sentidos: a visão, o tato, a audição e o olfato. A visita memorial aos espaços difere da de dona Zoraia: enquanto a primeira se apoia na escola de tai chi chuan, a segunda se apoia na presença da família e nas imagens que possui desses registros. O restaurante e a festa de bodas de sua mãe remetem às sensações provocadas pelo aroma da gastronomia. $\mathrm{O}$ amparo nas imagens, a descrição dos tecidos, a textura e a qualidade deles, classificam essa memória como tátil, visual e, mais do que isso, familiar, afetiva e aconchegante.
Segundo Assmann,

Mesmo quando os locais não têm em si uma memória imanente, ainda assim fazem parte da construção de espaços culturais da recordação muito significativos. E não apenas porque solidificam e validam a recordação, na medida em que a ancoram no chão, mas também por corporificarem uma continuidade da duração que supera a recordação relativamente breve de indivíduos, épocas e também culturas, que está concretizada em artefatos [...] (2011, p. 318).

A construção da memória não está na mesma linearidade que a vida útil de seu produtor. Enquanto a memória se autoproduz pela lembrança daqueles que vivienciaram e daqueles que tomaram conhecimento dessa lembrança, a vida útil do seu produtor não consegue explicitar a extensão dessa memória, pois ela avança um campo de abstração muito acelerado, estando condicionada à memória daqueles que não a vivenciaram. $\mathrm{E}$ isso se reporta claramente ao nosso objeto.

O espaço e os vestígios da memória, desde os anos 2000, remetem ao desafio de como entender essa memória. Percebemos que o registro, enquanto produtor de texto e imagem, ressignifica o valor dessa memória. Se antes tínhamos modos de fazer, ou seja, as sociabilidades dentro do clube (festas, encontros familiares, encontros administrativos, entre outros) e fora do clube, atualmente o valor simbólico foi corrompido pela ação do tempo. A edificação não caminha no mesmo passo da intenção de salvaguarda; sucumbiu à memória daqueles que não a vivenciaram, mas que têm a intenção de recriar abstratamente pela "memória dos locais". 
Segundo Assmann,

[...] a memória dos locais se diferencia claramente dos lugares da memória. É que, enquanto a memória dos locais é fixada em uma posição determinada, da qual ela não se desprende, os lugares da arte da memória se distinguem justamente por se poder transferí-los. A estrutura espacial da mnemotécnica funciona como uma planta ou um mapa, livre do seu local concreto de origem. Nessa força local de abstração, a mnemotécnica se aproxima de uma escrita que não dispõe letras em linha, mas constrói uma sintaxe espacial com imagens (2011, p. 333).

A imagem nesse aspecto reforça a memória dos locais, pois ela capta uma memória que trabalha os sentidos, ela não reforça a intencionalidade de quem fez a imagem no momento ocorrido do fato, que tão pouco privilegiou a ação de defesa promovida, mas está substanciada por significados que se mantiveram do passado e que se conflituam entre o presente e o futuro, bem como sob a ideia do que podem significar os destroços (Figura10). Como ressalta Flusser, "as imagens são mediações entre o homem e o seu mundo que, para ele, se tornou imediatamente inacessível" (2007, p. 142). Quando a imagem torna-se mediadora, acreditamos que o homem não percebe que está perdendo o controle dos vestígios do espaço no tempo e que, concomitantemente, fortalece uma memória, supostamente perceptível e intocável.
Figura 10 - Sala da Diretoria do CCRG, em 2005, quando o clube já se encontrava fechado e passando por ações judiciais

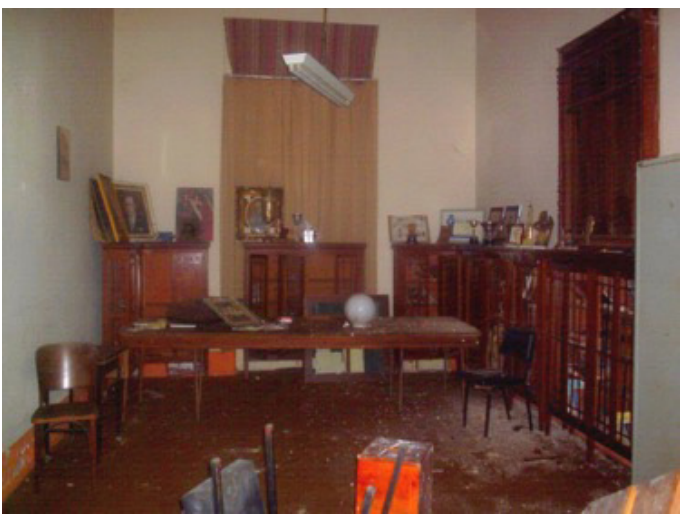

Fonte: acervo pessoal de Regys Macêdo.

A Figura 10 capta a sala da Diretoria do CCRG. Na imagem, há uma ambiguidade de poder e de afeto, o uso e o desuso do passado. $\mathrm{O}$ aspecto de abandono aponta um sentimento de "volto já", um pertencimento que se perdeu de si mesmo. Os bens de propriedade do clube estão em espera. Mas o que esperam? Senhor Regys, responsável pelo reguistro, nos relata o sentimento a respeito dessas imagens:

[...] naquela ocasião, já se via o clube interditado ou fechado, e sempre que eu passava ali, tinha vontade de voltar nele, entrar, ver como é que ele estava por dentro. Aí eu descobri que, naquela época, quem cuidava do clube era o barbeiro Ivo e tinha um outro rapaz que auxiliava ele nesse cuidado que tinha com o clube [...], conversando com ele, disse que tinha muita vontade de entrar lá, fazer fotos lá dentro, ver como está a situação do clube. Eu consegui que ele me acompanhasse até o clube, na parte interna. Naquele dia não tinha energia elétrica, então, as janelas, fechadas ou entreabertas, a iluminação 
era péssima [...]. Mas, dessa forma que eu consegui entrar no clube e fotografar o que era possível diante das circunstâncias que tinha lá [...] realmente é um sentimento de pesar. Sentimento para quem frequentou, eu não digo nos melhores momentos do clube, mas em um bom momento, bom momento para a nossa época como juventude e um bom momento pessoal para mim. Eu gostava de frequentar ali, namoradas tive ali, danças, essas coisas todas. $\mathrm{E}$, olhar um clube como mostra nas fotos, com uma deterioração, as coisas abandonadas, jogadas, as fotos mostram muito bem isso... É muito triste! Porque tu chegar em um ambiente que tu frequentou, tinha vida, tinha música, tinha juventude, e, entrar naquilo ali, uma penumbra! Uma falta de luz. Às vezes, em alguns momentos, tendo que pular obstáculos para passar de um lado para o outro, é um sentimento muito ruim que se tem. E o terceiro momento talvez seja o pior, que agora tu vê que caiu o teto, praticamente se perde as esperanças de que ele possa ser restaurado, dificilmente vai se conseguir que se assemelhe aquilo que era. Então, não existe outro sentimento que não de tristeza. $E$ as fotos servem, pelo menos não foram fotos do período bom, que não se tinha naquela época facilidade de fotografia que se tem hoje, mas são fotos que se registram o que chegou a ser próximo do que foi, em termos de estrutura, o caixeiral. ${ }^{10}$

É possível perceber nesse relato três importantes características: a primeira é o retorno ao clube, e isso é a relação de afeto; a segunda é o pesar diante da situação vigente; e a terceira é o registro fotográfico, como um processo de guarda sobre o tempo presente do objeto. O luto vai se instalando e reconfigurando a forma como o objeto passa a ser vivenciado no tempo em que estamos, ou seja, uma nova proposta de pertencimento daquele espaço, daquela memória do local. Além disso, o desafio da situação econômica que as sociedades brasileira, na cidade de Rio Grande não é diferente, e mundial enfrentam é um impeditivo para a efetivação de um projeto de restauro. Isso aumenta a distância do objeto recuperado, do seu uso e da sua inserção no contexto social.

Seguindo a lógica, é o texto da própria memória, uma micromemória que busca encontrar no presente o valor do passado, o simbolismo das práticas, dos lugares e das pessoas que passaram e perpassam diariamente, agora na sua ausência. Ou seja, aquilo que a câmera capturou é a representação dos vestígios, mas não da memória, enquanto objeto, pois o seu grupo produtor, os classistas caixeirais, já se dissociou na temporalidade entre o passado e o presente.

A imagem de um prédio pomposo, que representava o seu tempo e parte de um grupo da sociedade, permanece com essa representatividade diluída no próprio espaço temporal, pois não tem mais a presença do grupo na sua totalidade nem, tão pouco, os vestígios que sustentam essa memória.

Quando percebemos que a imagem é uma mediadora entre o presente e o passado, registramos o que Parente nos coloca:

Vivemos num mundo onde tudo circula. Tudo deve circular o mais rapidamente possível: os veículos, os enunciados, as imagens, as informações, os homens. No entanto, tudo parece estar no lugar, todas as diferenças se anulam, tudo se tornou intermutável. Os homens fazem viagens imóveis, como se eles mudassem de lugar para evitar uma mudança de "clima" (2011, p. 17). 
Essa circulação de que falamos sobre a imagem remete muito mais à percepção da informação do que aos vestígios propriamente ditos, mas o prédio continua desintegrando-se no mesmo local. A imagem que restou, certamente, serve como captura de um espaço no tempo, um momento que não se repetirá mais. Torna-se, assim, um processo de memória não vivenciado, mas vivido todos os dias pela abstração de sentido.

$\mathrm{O}$ clube enfrentou muitos dissabores em momentos distintos, principalmente durante a segunda metade do século XX. A partir do ano de 1988, com a nova Constituição brasileira, o clube, que já apresentava alguns problemas financeiros e dificuldades para manter seu patrimônio, viu nesse documento jurídico uma ameaça ao patrimônio consagrado por uma memória coletiva, já que permitia o acesso irrestrito de frequentadores, sem exigência de aprovação de sociedade ou, melhor, de um pertencimento ao clube.

Entre idas e vindas, acelerava-se a preocupação com o patrimônio do clube. Esse acesso livre às suas dependências acaba por quebrar um estigma social conservador, ou seja, a seleção natural, que era feita pelos estatutos e pela diretoria do clube, foi remodelada de maneira informal, porque também a situação financeira estava se agravando.

A situação do CCRG mudou drasticamente. Com as ações judiciais que o clube enfrentava e o encerramento de sua atividade, o prédio e o acervo ficaram por um tempo em espera de seu destino.

Em 2004, o prédio entrou no inventário de bens imóveis da cidade de Rio Grande, ${ }^{11}$ estando em acordo com a medida protetiva prevista no artigo 216 da Constituição federal.

O patrimônio material do clube foi designado para os trâmites do Ministério Público Estadual. ${ }^{12}$ Em 10 de dezembro de 2008, diante de representantes legais tanto do clube quanto da Prefeitura Municipal do Rio Grande, ficou definido que o patrimônio seria repassado à Prefeitura Municipal do Rio Grande e, especificamente, ao usufruto da Escola de Belas Artes Heitor de Lemos. A partir disso, deveria ser providenciado todo o processo de salvaguarda desse patrimônio.

O cotidiano tem apresentado outra linguagem de expressão quanto ao CCRG (Figura 11). O pertencimento recriado a partir do abandono do local está fragilizado e encontra em outros grupos uma sobreposição de memórias. O uso do local, entendido como inapropriado pelas condições que oferece, configura-se pelo abuso da memória que não consegue a ressignificação dentro do contexto presente.

Podemos, então, compreender pela "memória dos locais" que o poder simbólico tem uma força física ou moral, mas ele não tem significação, se não for analisado diante do meio social que o propaga. Esse meio caracteriza tal poder, seja econômico, político ou sociocultural.

O poder simbólico é o resultado do movimento da realidade e, de forma integrada, concebe o espaço e os elementos que habita (BOURDIEU, 2007, p. 8-9), mas essa relação nem sempre é muito clara no mundo social, pois pode parecer conflituosa a um olhar externo, embora, para quem a viva, tenha as suas justificativas para tal aceitação. 
O reconhecimento desse poder simbólico só é concebível quando da identificação dos símbolos, pois são eles que constroem a relação de significação entre dominante e dominado. A representação do indivíduo ou do grupo está na forma como se mostra o símbolo, e é essa a medida do poder simbólico. Cria-se um choque, quando queremos definir o teor da representação, pois existe uma construção de poder que promove a ação de uma pessoa ou do grupo e assim se faz representar.

Segundo Jacques Le Goff, "os materiais da memória podem apresentar-se sob duas formas principais: os monumentos, herança do passado, e os documentos, escolha do historiador" (2003, p. 526). Se a memória apodera-se dessas formas, faz desaperceber o quanto estagnamos a sobrevivência das memórias, pois, ao delimitarmos dois pontos distintos, corremos o risco de não aceitarmos as variantes dessas formas.

Mas a forma como se conduzem os documentos é a forma como são ressignificados dentro do seu contexto e, principalmente, fora dele.

Precisamos buscar o entendimento da relação monumento-documento dentro da esfera caixeiral. $\mathrm{O}$ que de fato nos provoca ter um entendimento sobre o que é monumento ou o que é documento (Figura 12)? Existe uma relação de poder entre ambos? Ou é apenas uma materialidade que ainda não foi significada dentro do seu espaço?
Figura 11 - Imagem aérea dos fundos do CCRG

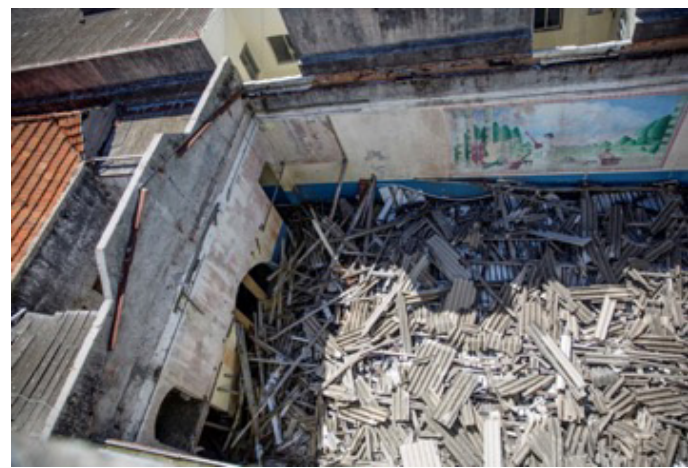

Fonte: acervo pessoal de Gianne Zanella Atallah e fotografia de Marcus Maciel (março de 2018)

Passados quatro anos desde a queda do telhado, as imagens (Figuras 11 e 12) mantêm um impacto tão importante como em 2014. Sem intenção direta, contribuímos para uma segregação memorial, devido ao fato de querermos não esquecer, não perder o bem cultural. Ao mesmo tempo, a sociedade como um todo torna-se responsável pela reivindicação silenciosa de uma memória dotada de restos.

Figura 12 - Imagem aérea da frente do CCRG

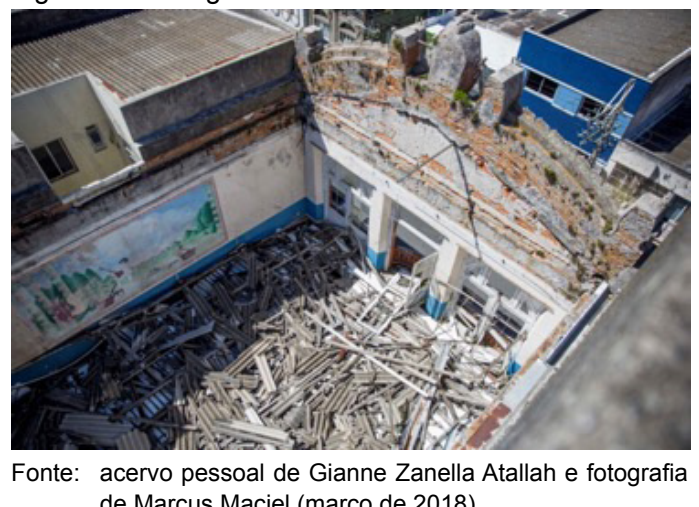
de Marcus Maciel (março de 2018). 
O Decreto $\mathrm{n}^{\circ} 15.205$ (PREFEITURA DE RIO GRANDE, 2018) determina o tombamento do prédio do antigo CCRG como patrimônio histórico e cultural do município de Rio Grande. De acordo com o artigo $2^{\circ}$, fica contemplada a fachada principal no processo de salvaguarda. Assim, não desejamos contestar um procedimento baseado em legislação e laudos técnicos para tal execução, mas esperamos uma reflexão da sociedade quanto a essa medida protetiva, já que o procedimento não acompanha a ação do tempo.

A reflexão social implica o envolvimento da sociedade e o seu entendimento sobre o objeto em estudo, como ele se configura na memória social de uma coletividade, que está além da memória coletiva do clube e de seus frequentadores. É preciso ressignificar como os sentidos da memória reconhecem o objeto dentro do espaço social, o seu valor de memória, não apenas enquanto espaço físico. É necessário também avaliar os perigos que essa edificação pode vir a causar aos transeuntes.

Há uma convocação sendo feita pelo clube, pois é preciso ouvir o objeto a respeito de sua memória histórica, uma memória que não se ajusta ao tempo presente e que se esconde no próprio passado. Se ainda não percebemos, estamos diante de um novo fechamento de portas, e isso cabe aos indivíduos discutir, refletir o valor de memória a partir do uso e do desuso do bem cultural.

É importante relacionar a edificação aos bens culturais produzidos, ou seja, o que está "por trás das portas". Ambos separadamente promovem uma descontinuidade do processo memorial, seja ele histórico ou social. Além de acervos pessoais e conversas com frequentadores, foi possível analisar documentos encontrados, para entendermos o que envolve a esfera do clube e sua trajetória.

\section{Considerações finais}

No que concerne ao nosso objeto, o CCRG, vislumbramos uma situação de ausência, de perda, de luto e de falta de diálogo com o próprio objeto. A compreensão de valor memorial está muito mais atrelada à presença do prédio, porque nele está o perigo do desgaste material, mas, implicitamente, está a reinvindicação do próprio objeto. Assim, essencialmente, o valor da entidade classista, os caixeiros, o seu envolvimento com a cidade de Rio Grande, atuando diretamente nos comércios local, regional e nacional, ficaram em segundo plano.

A relação de falar do outro, falar de si mesmo, do coletivo, é estar aprisionado pelo corpo-objeto. Entendemos que esse aprisionamento também é uma forma de memória, é o esquecimento, a luta por manter a perda de algo distante, inatingível, pois, enquanto a sede do clube estiver ali presencialmente, a perda estará distante do espírito, mas não do corpo.

Quando um meio de memória deixa de existir, tornamos sagrados os lugares de memória em que habitam os anseios de eternidade memorial. Mas até que ponto os lugares de memória trabalham a favor da memória social, quando, de fato, salvaguardam e "escondem" essa memória? Ao mesmo tempo em que protegemos, produzimos a ausência velada, o que está distante do meio passa a ter outro significado. 


\section{Abstract}

The article intends to establish a relationship between the present and the present with the object of the Clube Caixeiral de Rio Grande, RS, from the visual recognition in the context to which it is inserted, and how it influenced in frequenters that passed through there. This analysis intends to demonstrate how much the senses of memory can exert a favorable situation before the sources are they material (supports) and immaterial (souvenirs) from reference points that are established by the memory of the locals.

Keywords: Clube Caixeiral. Local memory. Rio Grande.

\section{Resumen}

El artículo pretende establecer una relación entre el presente y el presente con el objeto del Clube Caixeiral de Rio Grande, RS, desde el reconocimiento visual en el contexto al que se inserta, y cómo influyó en frecuentadores que pasaron por allí. Este análisis pretende demostrar cuánto los sentidos de la memoria pueden ejercer una situación favorable antes de que las fuentes sean materiales (soportes) e inmateriales (recuerdos) de puntos de referencia que se establecen por la memoria de los lugareños.

Palabras clave: Caixeiral. Memoria local. Rio Grande.

\section{Notas}

Livro de Atas $n^{\circ} 4$, p. 63 (verso) e 64 (frente).

2 Livro de Atas $n^{\circ}$ 4, p. 26 (verso) e 28 (frente e verso).

3 Livro de Atas $n^{\circ} 4$, p. 29 (frente e verso).

4 Livro de Atas $n^{\circ} 4$, p. 33 (verso) e 34 (frente).

5 Entrevista realizada em 22 out. 2017.

6 Entrevista realizada em 22 out. 2017.

7 Entrevista realizada em $1^{\circ}$ nov. 2017.

8 Entrevista realizada em $1^{\circ}$ nov. 2017.

9 Entrevista realizada em 21 out. 2017.

10 Entrevista realizada em 22 out. 2017.

11 A Ficha de Inventário de Bens Imóveis Municipais encontra-se disponível no link: <http:// www.riogrande.rs.gov.br/pagina/index.php/ inventario-de-bens-culturais $>$. Acesso em: 25 abr. 2018.

12 A Escola de Belas Artes Heitor de Lemos, que pertence à Secretaria da Educação de Rio Grande, foi a beneficiada com a transferência do prédio do CCRG e aguarda o restauro da construção, sendo que a obra está orçada atualmente em 13 milhões de reais.

\section{Referências}

\section{ASSMANN, Aleida. Espaços da re}

cordação: formas e transformações da memória cultural. Campinas: Editora Unicamp, 2011.

BATALHA, Claudio. Associações operárias, protesto e espaço urbano no Rio de Janeiro da Primeira República. In: AZEVEDO, Elciene et al. Trabalhadores na cidade: cotidiano e cultura no Rio de Janeiro e em São Paulo, séculos XIX e XX. Campinas/SP: Editora Unicamp, 2009. p. 251-269.

BOURDIEU, Pierre. O poder simbólico. Tradução de Fernando Tomaz. 10. ed. Rio de Janeiro: Bertrand Brasil, 2007.

FLUSSER, Vilém. O mundo codificado: por uma filosofia do design e da comunicação. Organização de Rafael Cardoso. Tradução de Raquel Abi-Sâmara. São Paulo: Cosac Naify, 2007. 
HOBSBAWN, Eric J.; RANGER, Terence (Org.). A invenção das tradições. Rio de Janeiro: Paz e Terra, 1997.

LE GOFF, Jacques. História e Memória. Campinas: Editora da Unicamp, 2003.

PARENTE, André (Org.). Imagem Máquina. Rio de Janeiro: Editora 34, 2011.

PREFEITURA DE RIO GRANDE. Decreto $n^{o}$ 15.205, de 24 de Janeiro de 2018. Declara de utilidade pública para fins de tombamento o prédio do antigo Clube Caixeiral como Patrimônio Histórico e Cultural do Município do Rio Grande. Disponível em: <https://leismunicipais.com.br/a/rs/r/ rio-grande/decreto/2018/1520/15205/ decreto-n-15205-2018-declara-de-utilidade-publica-para-fins-de-tombamento-o-predio-do-antigo-clube-caixeiral-como-patrimonio-historico-e-cultural-do-municipio-do-rio-grande>. Acesso em: 13 maio 2018.

TORNATORE, Jean-Louis. Patrimônio, memória, tradição, etc.: discussão de algumas situações francesas da relação com o passado. Revista Memória em Rede, Pelotas, v. 1, n. 1, p. 23-47, dez. 2009. Disponível em: <www. ufpel.edu.br/ich/memóriaemrede>. Acesso em: 14 jul. 2018. 